\title{
Two Phase Approximation Method Based on Bat Algorithm on Multi-objective Aggregate Production Planning
}

\author{
Pongchanun Luangpaiboon
}

\begin{abstract}
This paper proposes the two phase approximation method (2-PAM) based primarily on the concept of dynamic programming and metaheuristic. The multi-objective aggregate production planning (APP) model is solved by a pair of mathematical approaches. The desirability function approach was implemented to compromise all objectives of the aggregate production planning decision problem. The metaheuristic of bat and bee algorithms are first applied to provide the initial solutions in each stage. The dynamic programming approach is followed to combine all solutions. It was found that the results obtained from the proposed method based on bat algorithm can provide more effective and informative APP and more chance to achieve the optimal disaggregate plan when compared to the other variant of 2-PAM with bee algorithm.
\end{abstract}

Index Terms-Aggregate production planning, desirability function, two phase approximation algorithm, bat algorithm, bee algorithm, dynamic programming.

\section{INTRODUCTION}

Conventional optimisation algorithms search for a single optimum based on a weighted sum of all objectives. If these objectives simultaneously get better or worse, mathematical approaches such as linear, non-linear and dynamic programming can effectively can guarantee global optimum. However, in real world problems if the objectives are conflicting and there is an increase in the number of decision variables, then there is not a single optimum and the number of evaluations of the recursive functions would exponentially increase. In order to find satisfactory solutions for these hard optimisation problems, meta-heuristics have been introduced to overcome the deficiencies of conventional algorithms. Meta-heuristics are widely used to solve complex problems in industry and services, in various areas and in this case it is applied to the engineering problem. Aggregate production planning (APP) is concerned with the determination of production, inventory, and work force levels. It has been used to plan the future process capacity to meet fluctuating or uncertain sales demand requirements over a medium-time horizon ranging from six months to one year. Conventionally, the scarce resources of the company are assumed to be constant during the planning horizon of interest and the planning eff ort is oriented toward the best utilisation of those resources, given the external demand requirements. The APP

Manuscript received June 25, 2017; revised December 12, 2017. This work was supported in part by Thammasat University.

P. Luangpaiboon is with Industrial Statistics and Operational Research Unit (ISO-RU), Department of Industrial Engineering, Faculty of Engineering, Thammasat University, 12120, Thailand (e-mail: lpongch@engr.tu.ac.th). considers various operation strategies over appropriate scarce resources. They consist of hiring, overtime, layoffs, backorders, subcontracting and inventory level. An aim is to simultaneously optimise all customer requirements via multiple objectives over a fixed planning horizon. The data based on the APP model from Thai firm was coded for a computer simulation. An objective of this paper is to determine the proper scenario of the multi-objective aggregate production planning. This paper is organised as follows. Section II describes the multi-objective linear programming model of the APP. Sections III and IV are briefing about two variants of two phase approximation algorithms and computational results and analyses, respectively. The conclusion is also summarised and it is followed by acknowledgment and references.

\section{Multi-OBJective Linear Programming Model of AGgREGATE PRODUCTION PLANNING}

The aim of this study is to consider every fine detail associated with the production process to find an optimal production loading plan with maximal profit by fulfilling market demand. It is then necessary to aggregate all useful information being processed. A firm considers the aggregate production loading plan via the various ways to cope with information fluctuations as well as the cost associated with them. The plan consists of production quantities by experienced workers at regular time and at overtime, and by non-experienced workers for each period of time. With the plans, decision-makers can also determine varying the production rate by introducing outside subcontracting, accumulating seasonal inventories or planning backorders. Later on, the detailed production scheduling process provides the specific quantities to be produced of each individual item. To achieve the optimal plan, three goals are usually considered in the literatures. Multiple objectives for the aggregate production planning (APP) are production and inventory levels including a change of workforce levels under uncertain demands. The first includes material, direct labor, and overhead costs. The third is associated with changes in the production rate of hiring, training, and laying off personnel. Because this problem has relative objectives which need to compromise advantages or disadvantages each other. The multi-objective APP model is formulated with proper policies. The APP model consists of $\mathrm{N}$ product types over $\mathrm{T}$ planned periods with uncertain forecasted market demands. It is very important to determine the proper levels of hiring, layoffs, inventory, overtime work, subcontracting and back orders including other decision variables [1]-[3] 
Researchers have focused on various objectives such as maximal net profit, resource utilisation and customer service satisfaction. Some focus on minimal changes of production rate, workforce level and inventory investment. The following multi-objective linear programming model (MOLP) by Masuds and Hwang in 1980 is used in this current research [4].

$$
\begin{gathered}
\text { MIN } Z_{1}=\sum_{i=1}^{N} \sum_{t=1}^{T}\left(v_{i t} P_{i t}\right)+\sum_{t=1}^{T}\left(r_{t} W_{t}+h_{t} H_{t}+f_{t} F_{t}\right) \\
\operatorname{MIN} Z_{2}=\sum_{i=1}^{N} \sum_{t=1}^{T}\left(c_{i t} I_{i t}\right) \\
\operatorname{MIN~} Z_{3}=\sum_{t=1}^{T}\left(H_{t}+F_{t}\right)
\end{gathered}
$$

Subject to

$$
\begin{gathered}
P_{i t}+I_{i, t-1}-I_{i t}=d_{i t} \\
I_{i t} \geq I_{i t}^{M I N} \\
W_{t}-W_{t-1}-H_{t}+F_{t}=0 \\
W_{M I N} \leq W_{t} \leq W_{M A X} \\
P_{i t}-K_{i t} * W_{t} \leq 0 \\
P_{i t}, I_{i t}, W_{t}, H_{t}, F_{t} \geq 0 \\
W_{t}, H_{t}, F_{t} \in \text { Integer }
\end{gathered}
$$

This model consists of three minimal cost functions of the regular time production, product carrying or backordering and rates of labor level change. All expenses of raw materials and workers during production process are used to determine the regular time production cost. The decision maker (DM) compromises all three objectives of the APP by determining overall desirability. A desired degree of weight for each APP objective needs to be selected and the optimised decision variables could best compromise all desired objective functions based on the geometric mean [5]. Each objective function is transformed to the desirability function level with one side of minimisation. In each objective, when it is close to the desired value the desirability function value approaches 1 . If any objective is not at an acceptable level the desirability function value approaches zero [6].

\section{Two PhASE Approximation Algorithm (2-PAM)}

Dynamic programming algorithm (DP) aims to optimise complicated and large problem. The sequential procedures are to break the original down into a collection of simpler subproblems. The DP then solves each of those just once, and memorises these solutions in storage space to be a reference for later use. The DP will examine the previously solved subproblems and will merge these solutions to give the best so far solution for the given problem in specific time periods. Rosenblatt proposed a subprocedure for the DP to develop an optimal solution for the dynamic facility layout problem. With $T$ time periods or stages there are $(N !)^{T}$ solutions or states; where $N$ is the number of departments or locations. When considering all number of process layout combinations it is extremely time consuming. This problem is then simplified by applying only possible combinations in each period. Obviously, the recursive formulation is developed and the total cost for each of the layouts considered in the horizon is established be means of ignoring the worse solution with fewer stages. With Rosenblatt's dynamic programming subprocedure, in the planning discrete time period and the particular layout arrangement correspond to the stage and the state, respectively. Therefore, there are $N$ ! states in each of the $T$ stages.

The DP determines any layout arrangement for a given period that is excluded from the solution lists if the difference between the total cost of the arrangement and the cost of optimal static solution for that period is larger than the difference of the predetermined upper and lower bounds of the algorithm. Therefore, only the best static solutions for each stage need to be integrated. This algorithm can provide the optimal solutions for small problems but for very large and complex problems, exploring all possible states in each stage needs the capability software and hardware used to solve the problem. Let $N^{\prime}$ is the applicable number of the static assigning states in each stage. The main idea of this 2-PAM is different from the conventional one which provide the optimal solution when including all states in its procedure. However, for the 2-PAM when $N^{\prime}<N$ ! , it then cannot guarantee the optimum since there are not all the possible static states included in the procedure. Concerning the powerful tools for selecting the best $N$ ' layouts in each period metaheuristics are then considered and the best so far solutions should finally lead to better solutions [7]-[8]. In this case the bat and bee algorithms are proposed to determine the possible solutions in each stage (Fig. 1).

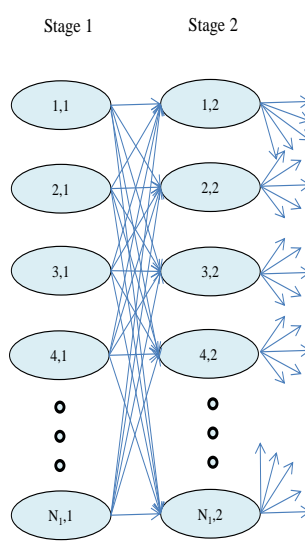

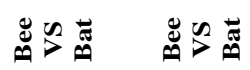

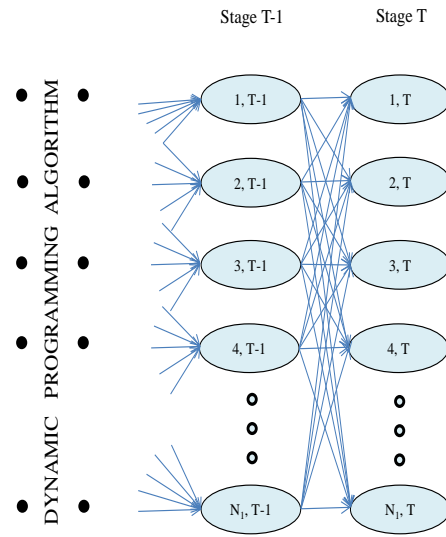

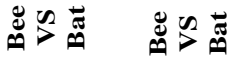

Fig. 1. The major structure of 2-PAM.

For the first variant of the 2-PAM or 2-PAMBAT, the the best static solutions are generated by Bat algorithm. It has been developed by Yang in 2010 [9]. This algorithm mimics advanced capability of the so called echolocation of bats to detect and avoid obstacles. Naturally, the bats randomly fly at a position $\left(\mathrm{x}_{\mathrm{i}}\right)$ with a velocity $\left(\mathrm{v}_{\mathrm{i}}\right)$, a pulse frequency $\left(\mathrm{f}_{\mathrm{i}}\right)$, wavelength $\left(\lambda_{i}\right)$, pulse rate $\left(r_{i}\right)$ and loudness $\left(A_{i}\right)$ to search for prey. These previous fascinating characteristics of bats are used to sense the distance, the difference between food/prey and background barriers [10]-[11]. The optimisation 
procedures inspired by the natural idealised rules of defined pulse frequency and rate are used to determine the optimum of engineering problems. While searching for the target, the emitted pulse wavelength and frequency can be automatically adjusted by the following equations.

$$
\begin{gathered}
f_{i}=\left(f_{\max }-f_{\min }\right) * \beta \\
v_{i}^{t}=v_{i}^{t-1}+\left(x_{i}^{t}-x_{g}\right)^{*} f_{i} \\
x_{i}^{t}=x_{i}^{t-1}+v_{i}^{t}
\end{gathered}
$$

where $\beta$ is a random variable randomly drawn from a uniform distribution between 0 and 1 . For the Bat, after generating the bat population and their all related characteristics a comparison among all $n$ solutions the current global best solution $\left(x_{g}\right)$ is located to adjust either $f_{i}$ or $\lambda_{i}$ parameter. For the local search part, a new solution for each bat is randomly generated around its average loudness. The choice of Bat parameters needs experimental design techniques to determine the proper levels and in this case the modified simplex method was proposed. The procedures of Bat algorithm can be summarised as the pseudo code shown in Fig. 2.

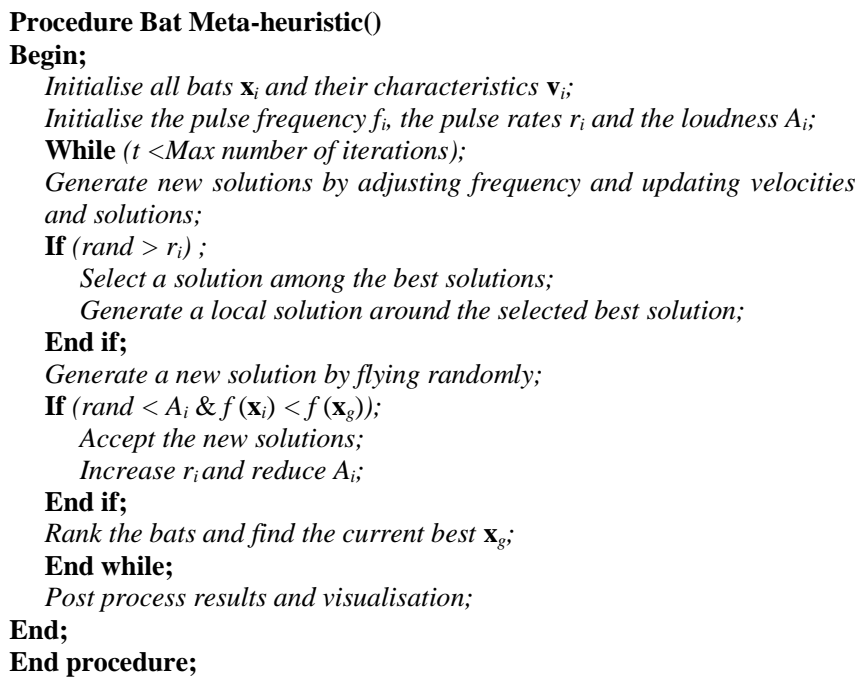

Fig. 2. Pseudo code of the Bat Meta-heuristic [12]

For the second variant, 2-PAMBEE, the possible solutions in each stage have been generated by with Bee algorithm. The population based search algorithm of Bee was first proposed by Pham and his colleague [13]. The Bee is inspired by the natural foraging behaviour of honey bees to successfully find the optimal solution with various engineering problems [14]-[16]. The Bee requires a number of parameters to be set, namely: number of scout bees $\left(\mathrm{x}_{1}\right)$, number of elite bees $\left(\mathrm{x}_{2}\right)$, number of patches selected out of $\mathrm{x}_{1}$ visited points $\left(\mathrm{x}_{3}\right)$, number of bees recruited for regions visited by "elite bees" $\left(\mathrm{x}_{4}\right)$ and number of bees recruited for the other $\left(\mathrm{x}_{3}-\mathrm{x}_{2}\right)$ selected patches $\left(\mathrm{x}_{5}\right)$. Fig. 3 shows the pseudo code for the Bee in its simplest form.

\section{Procedure Bee Meta-heuristic()}

Begin;

Randomly initialise the population;

Evaluate fitness values of the population;
While (stopping criterion not met)

Forming new population,

Select sites for neighbourhood search;

Recruit bees for selected sites (more bees for best sites) and evaluate fitness values;

Select the fittest bee from each patch;

Randomly assign remaining bees to search and evaluate their fitness values;

End while;

Post process results and visualisation;

End;

End procedure;

Fig. 3. Pseudo code of the Bee Meta-heuristic [17]

\section{COMPUTATIONAL RESUlts AND ANALySES}

The sequential procedures of the two phase approximation algorithm (2-PAM) were conducted to find the optimum of the multi-objective APP decision model by Masuds and Hwang. This algorithm applied the bat and bee algorithms to the first phase of the 2-PAM. The Bat and Bee parameters and their levels are given in Tables I and II, respectively. These proposed methods applied the overall desirability level as a moving trigger while searching for the optimum [18]. A computer simulation program on both variants of the 2-PAMBAT and 2-PAMBEE was implemented in a Visual

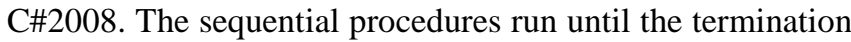
criteria is at the satisfaction state as shown below.

TABLE I: BAT ALGORITHM PARAMETERS AND PREFERRED LEVELS

\begin{tabular}{|c|c|c|}
\hline Parameter & Symbol & Level \\
\hline Virtual bats & $x_{1}$ & 40 \\
\hline Minimal frequency & $x_{2}$ & 0 \\
\hline Maximal frequency & $x_{3}$ & 100 \\
\hline Loudness decay factor & $x_{4}$ & 0.9 \\
\hline Pulse increase factor & $x_{5}$ & 0.87 \\
\hline
\end{tabular}

TABLE II: BEE ALGORITHM PARAMETERS AND PREFERRED LEVELS

\begin{tabular}{|l|c|c|}
\hline \multicolumn{1}{|c|}{ Parameter } & Symbol & Level \\
\hline Number of scout bees & $x_{1}$ & 40 \\
\hline Number of elite bees & $x_{2}$ & 10 \\
\hline $\begin{array}{l}\text { Number of patches selected out of } x_{1} \text { visited } \\
\text { points }\end{array}$ & $x_{3}$ & 20 \\
\hline $\begin{array}{l}\text { Number of bees recruited for regions visited } \\
\text { by "elite bees" }\end{array}$ & $x_{4}$ & 40 \\
\hline $\begin{array}{l}\text { Number of bees recruited for the other }\left(x_{3}-x_{2}\right) \\
\text { selected patches }\end{array}$ & $x_{5}$ & 20 \\
\hline
\end{tabular}

The comparisons are made for three scenarios based on inventory levels with the uniform distribution of $\mathrm{U}(0,200)$ or S1 and $U(200,400)$ or S2 including the minimal level of 400 or S3. Using the DFA of the APP an aim is to simultaneously minimise all three objectives over a 6-month period. At the S1, S2 and S3 scenarios, all objectives seemed to be better at $0.654,0.780$ and 0.787 on the overall levels of decision making desirability (D), respectively (Tables III). The 2-PAMBAT seemed to provide the better level of decision making desirability over all scenarios. When the 2-PAM concept and its two variants of 2-PAMBAT and 2-PAMBEE were compared, the 2-PAMBAT seems to be better in terms of speed of convergence. The basic idea is the innovative feature based on the echolocation behavior controlled by loudness and pulse rate which guarantee a quick convergence of the algorithm to the optimal solution. The 2-PAMBEE seemed to obtain the better satisfaction level only when resources are limited. So, carrying or backordering units are necessary. 
TABLE III: EXPERIMENTAL RESULTS CATEGORISED BY THE ALGORITHMS ON INDIVIDUAL DESIRABILITY FUNCTIONS OF THE FIRST $\left(\mathrm{d}_{1}\right)$, SECOND $\left(\mathrm{d}_{2}\right)$,

\begin{tabular}{c|c|c|c|}
\multirow{2}{*}{$\begin{array}{c}\text { ThiRD }\left(\mathrm{d}_{3}\right) \\
\text { Lentory } \\
\text { Level }\end{array}$} & Desirability & \multicolumn{2}{|c|}{ Algorithm } \\
\cline { 2 - 4 } S1 & $\mathrm{d}_{1}$ & 0.751 & 0.692 \\
\cline { 2 - 4 } & $\mathrm{d}_{2}$ & 0.378 & 0.324 \\
\cline { 2 - 4 } & $\mathrm{d}_{3}$ & 1.000 & 1.000 \\
\cline { 2 - 4 } & $\mathrm{D}$ & 0.654 & 0.598 \\
\hline \multirow{4}{*}{ S2 } & $\mathrm{d}_{1}$ & 0.605 & 0.587 \\
\cline { 2 - 4 } & $\mathrm{d}_{2}$ & 0.761 & 0.625 \\
\cline { 2 - 4 } & $\mathrm{d}_{3}$ & 1.000 & 1.000 \\
\cline { 2 - 4 } & $\mathrm{D}_{1}$ & 0.780 & 0.759 \\
\cline { 2 - 4 } & $\mathrm{d}_{1}$ & 0.556 & 0.342 \\
\cline { 2 - 4 } & $\mathrm{d}_{2}$ & 0.867 & 0.845 \\
\cline { 2 - 4 } & $\mathrm{d}_{3}$ & 1.000 & 1.000 \\
\cline { 2 - 4 } & $\mathrm{D}_{7}$ & 0.787 & 0.649 \\
\hline
\end{tabular}

When the performances of the 2-PAM with its variants of Bat and Bee were compared, the 2-PAMBAT seems to be better in terms of the mean desirability level of 0.7243 categorised by each objective function, but it is not statistically significant at $95 \%$ confidence interval (Table IV).

TABLE IV: ONE-WAY ANOVA: DESIRABILITY VERSUS TWO ALGORITHMS

\begin{tabular}{|l|c|c|c|c|c|}
\hline $\begin{array}{c}\text { Source of } \\
\text { Variation }\end{array}$ & DF & SS & MS & F & P-Value \\
\hline Algorithm & 1 & 0.002 & 0.002 & 0.444 & 0.514 \\
\hline Residual & 16 & 0.072 & 0.0045 & & \\
\hline Total & 17 & 0.074 & & & \\
\hline
\end{tabular}

\section{CONCLUSION}

The solutions or work force levels in the $\mathrm{t}$-th period $\left(\mathrm{W}_{\mathrm{t}}\right)$ based on preferable parameter settings of the Bat applied to the 2-PAM on all scenarios are shown in Table IV. The comparisons are made for three scenarios based on inventory levels with the uniform distribution of $\mathrm{U}(0,200)$ or $\mathrm{S} 1$ and $\mathrm{U}(200,400)$ or S2 including the minimal level of 400 or S3. From the numerical results, it seems that the selected choice of algorithm parameters is of importance for the convergence of the algorithm. Furthermore, an extension could be applied to enhance the performance of the 2-PAM when computational processes exceed the upper or lower limit.

TABLE V: BEST SO FAR SOLUTIONS OF THE APP MODEL ON THREE SCENARIOS OF INVENTORY LEVELS

\begin{tabular}{|c|c|c|c|c|c|c|c|c|c|}
\hline Product & \multicolumn{4}{|c|}{1} & \multicolumn{3}{|c|}{2} & \multicolumn{3}{|c|}{3} \\
\hline $\mathrm{W}_{\mathrm{t}}$ & $\mathrm{S} 1$ & $\mathrm{~S} 2$ & $\mathrm{~S} 3$ & $\mathrm{~S} 1$ & $\mathrm{~S} 2$ & $\mathrm{~S} 3$ & $\mathrm{~S} 1$ & $\mathrm{~S} 2$ & $\mathrm{~S} 3$ \\
\hline $\mathrm{W}_{1}$ & 0 & 0 & 0 & 0 & 0 & 0 & 0 & 0 & 0 \\
\hline $\mathrm{W}_{2}$ & 34 & 36 & 36 & 0 & 0 & 0 & 22 & 24 & 22 \\
\hline $\mathrm{W}_{3}$ & 43 & 45 & 44 & 0 & 0 & 0 & 42 & 40 & 38 \\
\hline $\mathrm{W}_{4}$ & 55 & 57 & 55 & 22 & 26 & 23 & 27 & 30 & 28 \\
\hline $\mathrm{W}_{5}$ & 55 & 57 & 55 & 49 & 50 & 50 & 4 & 5 & 4 \\
\hline $\mathrm{W}_{6}$ & 55 & 57 & 55 & 49 & 53 & 49 & 33 & 34 & 30 \\
\hline
\end{tabular}

\section{ACKNOWLEDGMENT}

An author would like to thank Faculty of Engineering, Thammasat University for the financial support.

\section{REFERENCES}

[1] A. Baykasoglu, "MOAPPS 1.0: Aggregate production planning using the multiple-objective tabu search," International Journal of Production Research, vol. 39, no. 16, pp. 3685-3702, 2001.
[2] R. C. Wang and T. F. Liang, "Application of fuzzy multi-objective linear programming to aggregate production planning," Computers \& Industrial Engineering, vol. 46, pp.17-41, 2004.

[3] B. Fahimnia, L. Luong and R. Marian, "Genetic algorithm optimisation of an integrated aggregate production-distribution plan in supply chains," International Journal of Production Research, vol. 50, no. 1, pp. 81-96, 2012.

[4] A. S. M. Masuds and C. L. Hwang, "An aggregate production planning model and application of three multiple objective decision methods," International Journal of Production Research, vol. 18, pp. 741-752, 1980.

[5] I. J. Jeong and K. J. Kim, "An interactive desirability function method to multiresponse optimisation," European Journal of Operational Research, vol. 195, no. 2, pp. 412-426, 2009.

[6] W. Wan and J. B. Birch, "Using a modified genetic algorithm to find feasible regions of a desirability function, Quality and Reliability Engineering International, vol. 27, no. 8, pp. 1173-1182, 2011.

[7] T. Dunker, G. Randons, and E. Westkamper, "Combining evolutionary computation and dynamic programming for solving a dynamic facility layout problem," European Journal of Operational Research, vol. 165, pp. 55-69, 2005.

[8] T. L. Urban, "A heuristic for the dynamic facility layout problem," IIE Transaction, vol. 25, no. 4, pp. 57-63, 1993.

[9] X. S. Yang, "A new meta-heuristic bat-inspired algorithm in nature inspired cooperative strategies for optimisation (NISCO 2010)," Studies in Computational Intelligence, Springer Berlin, vol. 284, pp. 65-74, 2010

[10] X. S. Yang, "Bat algorithm for multi-objective optimisation," Int. J. Bio-Inspired Computation, vol. 3, pp. 267-274, 2011.

[11] X. S. Yang and A. H. Gandomi, "Bat algorithm: a novel approach for global engineering optimisation," Engineering Computations, vol. 29, no. 5, pp. 464-483, 2012

[12] P. Luangpaiboon, "Determination of bat parameter levels on multi-objective aggregate production planning," in Proc. Asia-Pacific Conference on Engineering and Applied Science 2016 (APCEAS'16), Tokyo, Japan, 2016.

[13] D. T. Pham, A. J. Soroka, A. Ghanbarzadeh, E. Koç, S. Otri, and M. Packianather, "Optimising neural networks for identification of wood defects using the bees algorithm," in Proc. the IEEE International Conference on Industrial Informatics, Singapore, 2006.

[14] D. T. Pham, E. Koç, J. Y. Lee, and J. Phrueksanant, "Using the bees algorithm to schedule jobs for a machine," in Proc. the International Conference on Laser Metrology, CMM and Machine Tool Performance, LAMDAMAP, Euspen, Cardiff, UK, 2007.

[15] D. T. Pham, S. Otri, A. A. Afify, M. Mahmuddin, and H. Al-Jabbouli, "Data clustering using the bees algorithm," in Proc. the International Manufacturing Systems Seminar, Liverpool, UK, 2007.

[16] L. Ozbakir, A. Baykasoglu, and P. Tapkan, "Bee algorithm for generalized assignment problem," Applied Mathematics and Computation, vol. 215, pp. 3782-3795, 2010.

[17] P. Triwate and P. Luangpaiboon, "Bees algorithm for dynamic multi-zone dispatching in truck load trucking," in Proc. the IEEE International Conference on Industrial Engineering and Engineering Management, Macao SAR, P.R. China, 2010.

[18] P. Luangpaiboon and P. Aungkulanon, "Integrated approaches to enhance aggregate production planning with inventory uncertainty based on improved harmony search algorithm," International Journal of Mechanical, Aerospace, Industrial, Mechatronic and Manufacturing Engineering, vol. 7, no. 1, pp. 33-38, 2013.

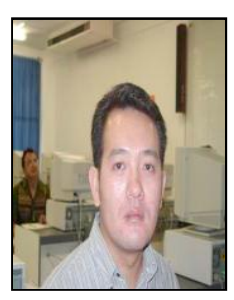

P. Luangpaiboon has been a lecturer, and a professor, in the Industrial Statistics and Operational Research Unit (ISO-RU), the Department of Industrial Engineering at Thammasat University, Thailand since 1995. He graduated his bachelor (1989-1993) and master degrees (1993-1995) in industrial engineering from Kasetsart University, Thailand and a $\mathrm{Ph}$. D. (1997-2000) in engineering mathematics from Newcastle upon Tyne, England.

$\mathrm{He}$ is a member of International Association of Computer Science and Information Technology (IACSIT) and International Association of Engineers (IAENG). His research interests consist of meta-heuristics, optimisation, industrial statistics, the design and analysis of experiments and response surface methodology. He received Kasetsart University Master Thesis Award in 1995 (Dynamic Process Layout Planning), Certificate of Merit for The 2009 IAENG International Conference on Operations Research (A Hybrid of Modified Simplex and Steepest Ascent Methods with Signal to Noise Ratio for Optimal Parameter Settings of ACO), Best Paper Award for the Operations Research Network Conference 2010 (An Exploration of Bees Parameter Settings via Modified 
Simplex and Conventional Design of Experiments), Certificate of Merit for The 2011 IAENG International Conference on Operations Research (Bees and Firefly Algorithms for Noisy Non-Linear Optimisation Problems), Best Student Paper Award for The 2011 IAENG International Conference on Industrial Engineering (Simulated Manufacturing Process Improvement via
Particle Swarm Optimisation and Firefly Algorithms) and Certificate of Merit for The 2013 IAENG International Conference on Industrial Engineering (Surface Lapping Process Improvement via Steepest Ascent Method Based on Factorial and Simplex Designs). 